\title{
BREVE HISTÓRIA SOBRE A EDUCAÇÃO DE JOVENS E ADULTOS NO BRASIL
}

\author{
Thyeles Borcarte Strelhow* \\ Pontifícia Universidade Católica do Rio Grande do Sul (PUCRS) \\ thyeles.strelhow@acad.pucrs.br
}

\section{RESUMO:}

Este artigo rebusca elementos históricos essenciais da educação brasileira de jovens e adultos para entendermos a sua situação atual. Assim, analisamos ações políticas que, no decorrer da historia, tentaram desenvolver o que hoje chamamos de EJA. Também procuramos explicitar as concepções referentes ao analfabetismo e à pessoa analfabeta, mostrando todo o preconceito impregnado no iletramento. Para tal, delimitamos a história a partir do Império até os nossos dias. Foi uma decisão própria do pesquisador, pois foi com o surgimento do Império que o Estado começou a dar maior atenção à educação. $\mathrm{O}$ objetivo deste artigo é buscar a reflexão sobre as atitudes tomadas no passado que têm suas seqüelas na atualidade, proporcionando uma reflexão sobre novos passos a serem tomados no presente e no futuro.

Palavras chaves: Educação de Jovens e Adultos; História; Educação; Ações Governamentais.

\section{BRIEF HISTORY ON YOUNG AND ADULT EDUCATION IN BRAZIL}

\begin{abstract}
:
This article seeks historical and essential elements concerning the Brazilian education of young people and adults in order to understand our current situation. This way, we analyze political actions that, throughout history, tried to develop what today we call EJA (Education of young people and adults). We also seek to explain conceptions about illiteracy and illiterate people, showing all the prejudice against illiterate people. For this, we bring historical fact since the Empire times up to our days. That was a researcher's decision, for it was after the Empire time that the Estate started to pay more attention to education. The goal of this research is to seek reflections concerning attitudes that happened in the past but still have consequences nowadays, in order to produce a new reflection about steps that can be taken in the present and in the future.

Keywords: Education of young people and adults; History; Education; Governmental Action.
\end{abstract}

\section{Introdução}

A Educação de Jovens e Adultos (EJA) é uma modalidade de ensino complexa porque envolve dimensões que transcendem a questão educacional. Até uns anos atrás, essa educação resumia-se à alfabetização como um processo compreendido em aprender a ler e escrever. O professor que se propõe a trabalhar com adultos deve refletir criticamente sobre sua prática, tendo também uma visão ampla sobre a sala de aula, sobre a escola em que vai trabalhar. Tem que ampliar suas reflexões sobre o ensinar, pensando sobre sua prática como um todo. Ele precisa resgatar junto aos alunos suas histórias de vida, tendo conhecimento de que há uma espécie de saber desses alunos que é o saber cotidiano, uma 
espécie de saber das ruas, pouco valorizado no mundo letrado e escolar. Freqüentemente o próprio aluno busca na escola um lugar para satisfazer suas necessidades particulares, para integrar-se à sociedade letrada, da qual não pode participar plenamente quando não domina a leitura e a escrita.

Um novo pensar sobre a educação de jovens e adultos traz para o âmbito escolar questões relativas ao processo histórico do aluno. Existem muitos motivos que levam esses adultos a estudar, como, exigências econômicas, tecnológicas e competitividade do mercado de trabalho. Vale destacar, que outras motivações levam os jovens e adultos para a escola, por exemplo, a satisfação pessoal, a conquista de um direito, a sensação da capacidade e dignidade que traz auto estima e a sensação de vencer as barreiras da exclusão.

Dessa forma, quando tomamos um assunto como objeto de uma investigação histórica, temos que levar em consideração a sua relevância para a construção do conhecimento. Em conformidade com isto, analisando a realidade da educação brasileira vemos que os números são desastrosos e preocupantes. Dados do IBGE, por exemplo, nos dão uma idéia de como foi tratado a educação de jovens e adultos no Brasil. A situação atual demonstra que o Brasil ainda não conseguiu garantir, na prática, a educação à todas as pessoas, como garante a constituição. Milhões de pessoas espalhadas por este imenso país, ainda não foram alcançadas por um dos direitos básicos de toda pessoa que é a educação. Mas porque existem tantas pessoas que foram excluídas do processo de alfabetização? O que gerou a posição social que tais pessoas ocupam? Quais foram as tentativas para garantir esse direito?

As respostas para essas e outras perguntas podemos possivelmente encontrar olhando para o passado. A História é necessária para que possamos viver o presente e olhar para o futuro. Esse é um dos objetivos da História, olhar para o passado para que possamos entender o presente. Para isso, faremos uma investigação que nos ajudará a compreender o processo histórico da educação de jovens e adultos e como lidamos com essa herança histórica na atualidade. Podemos adiantar que no decorrer da história, a educação do Brasil, em geral, foi tratada de forma inconseqüente pelas autoridades políticas do país. A educação brasileira foi sempre colocada em planos posteriores ao crescimento econômico e interesses das classes dominantes. Nos dias atuais, ainda não demos a devida atenção à educação, é só olharmos para o ensino público brasileiro que encontraremos escolas sucateadas e superpopuladas, corpo docente mal remunerado, um mínimo investimento numa educação de qualidade e assim por diante. É uma lástima a situação em que se encontra a educação brasileira.

Para o desenvolvimento deste artigo pretendemos trabalhar da seguinte forma. A priori, delimitamos os espaços históricos que queremos enfatizar. Basicamente buscaremos ressaltar o desenvolvimento histórico da educação de jovens e adultos a partir da década de 40, mas para elucidação procuraremos trazer algumas informações sobre sua situação no Império e início da República. Portanto, estruturemos este artigo em quatro partes principais. Num primeiro momento trabalharemos as influências de ações e pensamentos do período imperial e republicano na constituição da educação de jovens e adultos no Brasil. Num ponto posterior, pretendemos trabalhar o período de 40 até o golpe militar de 64. Aqui teremos como pano de fundo o surgimento de nosso grande pedagogo brasileiro Paulo Freire e sua teoria e prática que revolucionou o ensino brasileiro nesse período.

Num terceiro ponto trataremos da educação de jovens e adultos no período da ditadura militar. Para tal, analisaremos o Movimento Brasileiro de Alfabetização (Mobral) que foi criado com o objetivo de substituir a alfabetização utilizada pelos movimentos sociais antes do golpe. Por fim, procuraremos analisar a educação de jovens e adultos no 
surgimento da nova república (1988) e seu desenvolvimento até a atualidade. Para isso focalizaremos neste período, em especial, o EJA (Educação de Jovens e Adultos) que assume até à atualidade, junto ao Ministério da Educação, a alfabetização de jovens e adultos. A grosso modo, podemos afirmar que o trabalho, que em seguida será desenvolvido, não tem a pretensão de mostrar toda a História, mas de fixar-se em momentos históricos significativos que nos ajudará a ter uma idéia do desenvolvimento histórico da educação de jovens e adultos no Brasil e suas consequiências atuais.

\section{Do Império à República}

Se olharmos para a educação brasileira, desde o período colonial, poderemos perceber que ela tinha um cunho específico direcionado às crianças, mas "indígenas adultos foram também submetidos a uma intensa ação cultural e educacional"1. A Companhia Missionária de Jesus, tinha a função básica de catequizar (iniciação à fé) e alfabetizar na língua portuguesa os indígenas que viviam na colônia brasileira. Com a saída dos jesuítas do Brasil em 1759, a educação de adultos entra em colapso e fica sob a responsabilidade do Império a organização e emprego da educação. A identidade da educação brasileira foi sendo marcada então, pelo o elitismo que restringia a educação às classes mais abastadas. As aulas régias (latim, grego, filosofia e retórica), ênfase da política pombalina, eram designadas especificamente aos filhos dos colonizadores portugueses (brancos e masculinos), excluindo-se assim as populações negras e indígenas. ${ }^{2}$ Dessa forma, a história da educação brasileira foi sendo demarcada por uma situação peculiar que era o conhecimento formal monopolizado pelas classes dominantes.

Essa contextualização nos dá a situação em que se iniciou a educação brasileira. É importante lembrar que a partir da constituição Imperial de 1824 procurou-se dar um significado mais amplo para a educação, garantindo a todos os cidadãos a instrução primária. No entanto, essa lei, infelizmente ficou só no papel. ${ }^{3}$ Havia uma grande discussão em todo o Império de como inserir as chamadas camadas inferiores (homens e mulheres pobres livres, negros e negras escravos, livres e libertos) nos processos de formação formais. E a partir do Ato Constitucional de 1834, ficou sob a responsabilidade das províncias a instrução primaria e secundária de todas as pessoas, mas que foi designada especialmente para jovens e adultos. É importante ressaltar que a educação de jovens e adultos era carregada de uma princípio missionário e caridoso. O letramento destas pessoas era um ato de caridade das pessoas letradas às pessoas perigosas e degeneradas. "Era preciso 'iluminar' as mentes que viviam nas trevas da ignorância para que houvesse progresso" (STEPHANOU; BASTOS (orgs), 2005, p. 261). A alfabetização de jovens e adultos deixa de ser um direito para ser um ato de solidariedade. ${ }^{4}$

A idéia da pessoa analfabeta como dependente tomou força com o período que preconizava a República. Em 1879, a Reforma Leôncio de Carvalho caracterizava o analfabeto como dependente e incompetente. Posteriormente em 1881, a Lei Saraiva corrobora com a idéia da Reforma de Leôncio de Carvalho restringindo o voto às pessoas alfabetizadas. Rui Barbosa, em 1882, postula que "os analfabetos são considerados, assim, como crianças, incapazes de pensar por si próprios". Instala-se uma grande onda de preconceito e exclusão da pessoa analfabeta. A frase de Rui Barbosa está carregada de preconceito, pois podemos perceber que há uma desvalorização da criança em considerá-la incapaz e do adulto de reduzi-lo a esta situação de incapacidade.

Sob estas discussões a constituição republicana foi construindo-se e em 1891, o que era ruim ficou ainda pior, o voto foi restrito à pessoas letradas e com posses, uma pequena minoria. ${ }^{6}$ Agora estava garantida na lei a discriminação e exclusão da pessoa analfabeta. 
Ao invés de evoluir para uma democracia, reduzia-se à uma República dominada por poucos. $\mathrm{O}$ voto que anteriormente era restrito às pessoas que possuíssem uma determinada renda, agora além da renda teriam de ser alfabetizadas. $\mathrm{O}$ movimento contrário à evolução é gritante, uma situação lastimável da república brasileira.

Com o início do século XX houve uma grande mobilização social que pretendia exterminar este mal, o analfabetismo. Começou-se assim, a culpar as pessoas analfabetas da situação de subdesenvolvimento do Brasil. Em 1915 foi criada a Liga Brasileira contra o Analfabetismo que pretendia lutar contra a ignorância para estabilizar a grandeza das instituições republicanas. Na Associação Brasileira de Educação (ABE), as discussões giravam em torno de uma luta contra esta calamidade pública que tinha se instalado. $\mathrm{O}$ analfabetismo era considerado uma praga que deveria ser exterminada. No âmago destas discussões estava presente a idéia de que as pessoas que não eram alfabetizadas deveriam procurar se alfabetizar. Era necessário tornar a pessoa analfabeta um ser produtivo que contribuísse para o desenvolvimento do país.

Paralelamente ao desenvolvimento educacional do Brasil podemos perceber a seguinte situação econômica em que estava vivendo a sociedade brasileira. A característica peculiar do momento econômico brasileiro, herdado do período imperial, era de uma economia que girava em torno do sistema agrário-exportador. A configuração econômica brasileira estava voltada para o mercado externo, "tipo exportador". Assim, com a crise cafeeira de 1929 há uma mudança na economia, o capital passa a ser empregado não só no sistema agrário, mas também estimula-se o investimento no setor industrial. ${ }^{8}$ Nesse período, entre a Proclamação da República e o início da década de 20, a democracia brasileira vai se fortalecendo "segundo os desígnios dos setores vinculados à burguesia agrário-comercial dos centros produtores da região centro-sul, onde a burguesia paulista detinha uma posição hegemônica" (MANFREDI, 1981, p.28). Na década de 20, há uma revolução na política brasileira articulada pela classe média urbana e setores da própria classe dominante que não tinham interesse no comércio do café. Com a vitória da Aliança Liberal (Rio Grande do Sul, Minas Gerais e Paraíba) em 1929, a política brasileira se encontrava num "vazio de poder, porque havia um colapso no poder da burguesia cafeeira e uma incapacidade das demais frações para assumi-lo" (FAUTO. 1972, p. 112). Junto à essa mudança econômica começa-se a mudar algumas coisas no âmbito da educação com o surgimento dos ideais da Escola Nova e posteriormente as ações da Pedagogia de Paulo Freire em conjunto com os movimentos sociais.

\section{Da década de 40 à Marca dos Movimentos Sociais}

Podemos perceber que este descaso com a educação levou o Brasil a alcançar a incrível marca de $72 \%$ de analfabetismo em $1920 .{ }^{9}$ Em 1934, foi criado o Plano Nacional de Educação que previa o ensino primário integral obrigatório e gratuito estendido às pessoas adultas. Esse foi o primeiro plano na história da educação brasileira que previa um tratamento específico para a educação de jovens e adultos. ${ }^{10} \mathrm{E}$ foi a partir da década de 40 e com grande força na década de 50 que a educação de jovens e adultos voltam a pautar a lista de prioridades necessárias do país. Em 1938 foi criado o INEP (Instituto Nacional de Estudos Pedagógicos) e a partir de suas pesquisas e estudos, foi fundando em 1942 o Fundo Nacional do Ensino Primário com o objetivo de realizar programas que ampliasse e incluísse o Ensino Supletivo para adolescentes e adultos. Em 1945, este fundo foi regulamentado, estabelecendo que $25 \%$ dos recursos fosse empregado na educação de adolescentes e adultos. ${ }^{11}$ 
Desde o início da década de 40, a educação de jovens e adultos estava em alta. Em 1946 surge a Lei Orgânica do Ensino Primário que previa o ensino supletivo, ${ }^{12}$ e em 1947 surgiu um programa, de âmbito nacional, visando atender especificamente às pessoas adultas, com a criação do SEA (Serviço de Educação de Adultos). A finalidade do SEA era de reorientar e coordenar, no geral, os trabalhos dos planos anuais do ensino supletivo para adolescentes e adultos analfabetos. Esse movimento que durou até fins da década de 50 foi denominado de Primeira Campanha Nacional de Educação de Adultos. ${ }^{13}$ Porém, é discutível o método pedagógico utilizado que homogeneizava seus alunos sem a preocupação dos contextos em que estavam inseridos. Foram criados guias de leituras, que possuíam em seu conteúdo, pequenas frases e textos sobre comportamento moral e com informações sobre saúde, técnicas de trabalho e higiene. ${ }^{14}$

Um dos motivos para o surgimento da Primeira Campanha Nacional de Alfabetização foi a imensa pressão internacional para a erradicação do analfabetismo nas ditas "nações atrasadas". Essa pressão internacional se deu pela criação da ONU (Organização das Nações Unidas) e da UNESCO (Órgão das Nações Unidas para a Educação, Ciência e Cultura) após o fim da segunda guerra mundial em 1945. A orientação da ONU e da UNESCO era de que a educação era o meio de desempenhar o desenvolvimento das "nações atrasadas". ${ }^{15}$ Isso demonstra que os programas de educação instalados estavam preocupados mais na quantidade de pessoas formadas do que a qualidade. Além dessas recomendações, era plausível ao momento histórico interno brasileiro o aumento de pessoas que, diante da lei, pudessem exercer o direito do voto no caminho da democratização. ${ }^{16}$

Outro fator, que contribuiu à uma educação de massa, é a consideração da pessoa analfabeta como ignorante, incapaz, cabeça dura, sem jeito para as letras. ${ }^{17}$ Nesse caso, as pessoas adultas que não fossem alfabetizadas deveriam receber a mesma educação empregada na educação de crianças, pois esses adultos analfabetos estavam inaptos a compreender. Mas ao mesmo tempo que se considerava adultos como crianças, tinha-se a idéia de que os adultos eram mais fáceis de alfabetizar, por isso, os alfabetizadores não necessitariam de formação especializada, qualquer pessoa alfabetizada poderia exercer a função de maneira voluntária. ${ }^{18}$ Dessa idéia surgiu dois documentos que abordavam o tema do voluntariado, em 1948, Relação com o Público e o Voluntariado e em 1960 o Manual do Professor Voluntário - Ilustrações para o Ensino de Leitura e Linguagem Escrita. ${ }^{19}$

Em 1952, foi criada a Campanha Nacional de Educação Rural (CNER), para atender as populações que viviam no meio rural. ${ }^{20} \mathrm{E}$ em 1958 , com a realização do II Congresso Nacional de Educação de Adultos no Rio de Janeiro, começou-se a dar passos em direção da discussão de um novo método pedagógico utilizado na educação de adultos. Os educadores sentiram a necessidade de romper com os preconceitos que envolviam as pessoas analfabetas. È nessa época que começamos a conhecer um dos maiores pedagogos do país, Paulo Freire. Começa-se aqui a moldagem da pedagogia de Freire, já no Seminário Regional (preparatório ao congresso), realizado em Recife, Freire chamava a atenção de que o desenvolvimento educativo deve acontecer contextualizado às necessidades essenciais das pessoas educadas, "com" elas e não "para" elas. ${ }^{21}$ Nesse sentido, as pessoas analfabetas não deveriam ser vistas como imaturas e ignorantes, além disso, "o problema do analfabetismo não era o único nem o mais grave da população: as condições de miséria em que vivia o não alfabetizado é que deveriam ser problematizadas" (STEPHANOU; BASTOS (orgs), 2005, p. 268). Como resposta oficial às críticas do Congresso, foi criada em 1958 a Campanha de Erradicação do Analfabetismo (CNEA), com a proposta de criar projetos-pólos com atividades que integrassem a realidade de cada município e servissem 
de modelo para expandir-se pelo país, mas pouco se diferenciou das campanhas anteriores. $^{22}$

O fím da década de 50 e início da década de 60 foi marcado por uma grande mobilização social em torno da educação de adultos. Podemos citar vários movimentos sociais criados nesse período, tais como: "Movimento de Educação de Base" (1961CNBB), Movimento de Cultura Popular do Recife (1961), Centros Populares de Cultura (UNE), Campanha de Pé no chão Também se Aprende (Prefeitura de Natal). ${ }^{23}$ Esses programas, através da influência da pedagogia freiriana, identificavam o analfabetismo "não como a causa da situação de pobreza, mas como efeito de uma sociedade injusta e não-igulitária" (STEPHANOU; BASTOS (orgs), 2005, p. 269). Esses movimentos, procuravam reconhecer e valorizar o saber e a cultura popular, considerando assim, a pessoa não alfabetizada uma produtora de conhecimento. Com a grande repercussão desses movimentos de alfabetização popular, foi encerrada a CNEA e no mesmo ano Paulo Freire foi indicado para elaborar o Plano Nacional de Alfabetização junto ao Ministério da Educação. No entanto, com o Golpe Militar em 31 de março de 1964, esse plano foi interrompido. $^{24}$

Paralelamente à todo esse desenvolvimento educacional, a economia brasileira vivia um momento onde o setor industrial passa por um grande desenvolvimento, substituindo o modelo de exportação agrária para um modelo de importações. É nessa época de 1930-1964 que o Estado brasileiro passa a ser "um dos principais centros de decisão ao nível da política econômica" (MANFREDI, 1981, p. 27). Outra característica importante deste estágio é o surgimento do fenômeno populista com Vargas, Juscelino Kubitschek, Jânio Quadros e João Goulart. Esse populismo é fruto de uma herança deixada pelo período anterior, com o esvaziamento do poder brasileiro, dá-se margem ao surgimento de figuras "salvadoras da pátria".

As táticas dos governos populistas, que oscilavam entre a atenção às reivindicações populares e a manutenção do status quo, proporcionou um clima favorável à participação política dos movimentos sociais. Nos grandes centros urbanos surgem a luta para evitar o rebaixamento do poder aquisitivo salarial. Há um grande empenho de grupos intelectuais, organizações de esquerda, entidades estudantis e algumas entidades ligadas às igrejas para a mobilização e organização de trabalhadores dos setores urbanos e agrícolas para uma maior participação política. Nesse sentido, o engajamento dos setores sociais na luta por seus direitos e na política, é importante, porque surge nesses grupos a educação de base voltada para a educação de adultos, como uma tática de atuação política. ${ }^{25}$

\section{Do Militarismo à Nova República}

Chegamos à um dos momentos mais negros da história brasileira, o Golpe Militar de 1964. Com o Militarismo, os programas que visavam a constituição de uma transformação social foram abruptamente interrompidos com apreensão de materiais, detenção e exílio de seus dirigentes. Retoma-se, nessa época, a educação como modo de homogeneização e controle das pessoas. O governo militar, então, criou o Movimento Brasileiro de Alfabetização (Mobral), em 1967, com o objetivo de alfabetizar funcionalmente e promover uma educação continuada. Com esse programa a alfabetização ficou restrita à apreensão da habilidade de ler e escrever, sem haver a compreensão contextualizada dos signos. ${ }^{26}$ Configurava-se assim, o sentido político do Mobral, que procurava responsabilizar o indivíduo de sua situação desconsiderando-o do seu papel de ser sujeito produtor de cultura, sendo identificado como uma "pessoa vazia sem 
conhecimento, a ser 'socializada' pelos programas do Mobral" (MEDEIROS, 1999, p. 189).

O Mobral procura restabelecer a idéia de que as pessoas que não eram alfabetizadas eram responsáveis por sua situação de analfabetismo e pela situação de subdesenvolvimento do Brasil. Um dos slogans do Mobral era: "você também é responsável, então me ensine a escrever, eu tenho a minha mão domável" (STEPHANOU; BASTOS (orgs), 2005, p. 270). Junto a essa idéia, também houve recrutamento de alfabetizadores sem muita exigência, rebuscando a idéia de que para educar uma pessoa adulta é necessário ser apenas alfabetizada, sem entender o método pedagógico. Por fim, o Mobral foi extinto em 1985, com a chegada da Nova República, e seu final foi marcado por denúncias sobre desvios de recursos financeiros, culminando numa CPI (Comissão Parlamentar de Investigação). Muitas pessoas que se alfabetizaram pelo Mobral acabaram desaprendendo a ler e escrever. ${ }^{27}$

No período militar, a economia brasileira é determinada pela redução do investimento, a diminuição da entrada de capital estrangeiro, a queda da taxa de lucro e a aceleração do processo inflacionário. Pode-se dizer que estas características são frutos de uma tentativa frustrada da fixação de um modelo econômico autônomo. Além disso, a economia brasileira se encontrava numa grande crise de nível conjuntural, que acabou continuando no início da Nova República. ${ }^{28}$

Porém, poderemos ver que com a República Nova há a primeira explicitação legal dos direitos dos cidadãos que não foram escolarizados na idade ideal, como destaca Oliveira (2007, p. 4):

O inciso I do artigo 208 indica que o Ensino Fundamental passa a ser obrigatório e gratuito, "assegurada, inclusive, sua oferta gratuita para todos os que a ele não tiveram acesso na idade própria". Em seu artigo 214, a Carta Magna indica também a que legislação "estabelecerá o Plano Nacional de Educação, de duração plurianual, visando à articulação e ao desenvolvimento do ensino em seus diversos níveis e à integração das ações do poder público que conduzam à • I - erradicação do analfabetismo, • II - universalização do atendimento escola.

Cabe lembrar também, que na emenda constitucional $\mathrm{N}^{\circ} 14 / 96$ fica estabelecido que a União deverá investir nunca menos que trinta por cento do caput do artigo 212 para a erradicação do analfabetismo e manutenção e desenvolvimento do ensino fundamental. ${ }^{29}$

Assim, com a nova constituição de 1988, prevê-se que todas as pessoas tenham acesso à educação, sendo reforçada na Lei de Diretrizes e Bases da Educação Nacional (LDB) $\mathrm{n}^{\circ}$ 9394/96 de 20 de dezembro de $1996 .{ }^{30}$ De acordo com a LDB,${ }^{31}$ é determinado que o Plano Nacional de Educação seja elaborado em concordância com a Declaração Mundial de Educação para Todos, e com base na LDB, foi constituída a Educação de Jovens e Adultos como modalidade de ensino através da resolução CNB/CEB No 1 , de 5 de julho de 2000, que estabelece as Diretrizes Curriculares Nacionais para a Educação de Jovens e Adultos. Ressalta-se ainda o direito a jovens e adultos à educação adequada às suas necessidades peculiares de estudo, e ao poder público fica o dever de oferecer esta educação de forma gratuita a partir de cursos e exames supletivos. ${ }^{32}$

Com o fim do Mobral em 1985, surgiram outros programas de alfabetização em seu lugar como a Fundação Educar, que estava vinculada especificamente ao Ministério da Educação. O seu papel era de supervisionar e acompanhar, junto às constituições e secretarias, o investimento dos recursos transferidos para a execução de seus programas. No entanto, em 1990, com o Governo Collor, a Fundação Educar foi extinta sem ser criado nenhum outro projeto em seu lugar. A partir daí então, começou a ausência do governo 
federal nos projetos de alfabetização. Os municípios passam a assumir a função da educação de jovens e adultos. Paralelamente, foram feitas muitas experiências de universidades, movimentos sociais e organizações não-governamentais em relação à educação. Há uma imensa pluralidade de práticas metodológicas baseadas em descobertas, lingüísticas, psicológicas e educativas recentes (como os estudos de Emília Ferero), que contribuíram para a criação de métodos de alfabetização. ${ }^{33}$

Entre os movimentos que surgiam no início da década de 90, podemos destacar o Movimento de Alfabetização (Mova), que procurava trabalhar a alfabetização a partir do contexto sócio-econômico das pessoas alfabetizandas, tornando-as co-participantes de seu processo de aprendizagem. Somente em 1996, surge novamente um programa nacional de alfabetização promovido pelo governo federal. No entanto, com o Programa Alfabetização Solidária (PAS), parecia que estávamos tendo um replay das campanhas das décadas de 40 e 50. As principais críticas a este plano eram que:

além de se tratar de um programa aligeirado, com alfabetizadores semipreparados, reforçando a idéia de que qualquer um sabe ensinar, tinha como um de seus pressupostos a relação de submissão entre o Norte-Nordeste (subdesenvolvido) e o Sul-Sudeste (desenvolvido). Além disso, com a permanente campanha 'Adote um Analfabeto', o PAS contribuiu para reforçar a imagem que se faz de quem não sabe ler e escrever como uma pessoa incapaz, passível de adoção, de ajuda, de uma ação assistencialista (STEPHANOU; BASTOS, 2005, p. 272).

Em 1998, surge o Pronera (Programa Nacional de Educação na Reforma Agrária), com o objetivo de atender às populações situadas nas áreas de assentamento. Este programa estava vinculado essencialmente ao Incra, universidades e movimentos sociais. Em 2003, o governo federal lançou o Programa Brasil Alfabetizado, que no início tinha característica de mais uma campanha, com ênfase no trabalho voluntário, prevendo erradicar o analfabetismo em 4 anos, tendo uma atuação sobre 20 milhões de pessoas. No entanto, em 2004, com a mudança do Ministro da Educação, o programa foi reformulado, retirando-se a meta de erradicar o analfabetismo de 4 anos e a duração dos projetos de alfabetização foi ampliada em 2 meses, de 4 meses para 8 meses. ${ }^{34}$

Assim, chegamos ao século XXI com uma alta taxa de pessoas que não têm o domínio sobre a leitura, a escrita e as operações matemáticas básicas, tendo:

quase 20 milhões de analfabetos considerados absolutos e passam de 30 milhões os considerados analfabetos funcionais, que chegaram a freqüentar uma escola, mas por falta de uso de leitura e da escrita, tornaram à posição anterior. Chega, ainda, à casa dos 70 milhões os brasileiros acima dos 15 anos que não atingiram o nível mínimo de escolarização obrigatório pela constituição, ou seja, o ensino fundamental. Somam-se a esses os neo analfabetos que, mesmo freqüentando a escola, não conseguem atingir o domínio da leitura e da escrita (STEPHANOU; BASTOS, 2005, p. 273).

\section{Considerações Finais}

Este referencial histórico nos dá embasamento para uma análise da situação atual da educação brasileira. É assustador o número de pessoas que lêem um texto simples e não entendem o sentido apresentado pelo autor. Podemos dizer, que essa é uma herança de todo o tratamento que a educação brasileira sofreu ao decorrer de sua história. É lamentável que reduzimos a alfabetização à apreensão dos signos sem a apreensão dos significados. $\mathrm{O}$ 
mais problemático ainda é encontrar em nosso contexto escolar a continuação desse processo de educação que, ao invés de produzir leitores críticos e que consigam entender as intenções dos textos, produzem pessoas alienáveis que apenas funcionalmente estão alfabetizadas. $^{35}$

Todos esses projetos e planos visavam o avanço na educação e a erradicação do analfabetismo no Brasil, no entanto, o nível de organização desses planos é surpreendentemente atabalhoado. Criava-se projetos e mais projetos e sem ter, muitas vezes, o tempo necessário para surtir efeito, eram desmantelados ou trocados por outros projetos. Mas o que temos que destacar também, com bastante ênfase, que o movimento de políticas públicas propostas pelos governos no decorrer dos anos, aconteceram por causa de muita pressão tanto internacional, com os órgãos internacionais como UNESCO e ONU, tanto quanto nacional com os movimentos populares. Não são poucos os movimentos, campanhas, projetos, programas que surgiram a partir de um esforço de algum movimento de base, que além de ensinar os códigos de linguagem procuravam tornar significativo a existência do indivíduo na sociedade através do empoderamento através do conhecimento.

Com alguns fatos históricos como estes discorridos neste artigo, podemos brevemente avaliar nossas ações educativas atuais, através da história, que como nação vivemos. Temos que rebuscar o que deu certo em nosso contexto e o que foi apenas uma tentativa vã. Como profissionais da educação ou como pessoas sujeitas da história envolvidas na educação como um ato político, temos que nos perguntar: que educação queremos vivenciar? O que queremos com a Educação de Jovens e Adultos? Qual sua intenção? Queremos uma educação que sirva somente para instrumentalizar a pessoa ao mercado de trabalho ou queremos pessoas também que reflitam sobre sua situação social e do país? Queremos pessoas pensantes, críticas ou pessoas que são alienadas de seus direitos, como o de ter uma vida digna. A que e a quem a educação, de forma geral, está servindo? Penso que, como pessoas capazes de mudar a situação em que nos encontramos, de mudar um sistema de pensamento, de transformar toda uma realidade, temos a responsabilidade de querermos e sermos pessoas que pensam e que a partir da educação sejam instrumentalizadas a refletirem sobre sua ação como sujeitos e sujeitas da história.

\section{Referências}

AGUIAR, Raimundo Helvécio Almeida. Educação de Adultos no Brasil: políticas de (des)legitimação. Tese de Doutorado. Orientação Lúcia Mercês de Avelar. Campinas: Universidade Estadual de Campinas, 2001.

ANTUNES, Denise Dalpiaz. Relatos significativos de professores e alunos na Educação de Jovens e Adultos e sua auto-imagem e auto-estima. Porto Alegre: Tese de Mestrado pela Pontifícia Universidade Católica do Rio Grande do Sul, 2006.

DI PIERRO, Maria Clara; GRACIANO, Mariângela. A Educação de Jovens e Adultos no Brasil: informe apresentado à oficina regional da UNESCO para América Latina y Caribe. São Paulo: Ação Educativa - Assessoria, Pesquisa e Informação, 2003. http://www.acaoeducativa.org.br/downloads/relorealc.pdf acessado em 02 de junho de 2007. 
DI PIERRO, Maria Clara; JOIA, Orlando; RIBEIRO, Vera Masagão. Visões da Educação de Jovens e Adultos no Brasil. Cadernos Cedes, ano XXI, nº 55, 2001, p. 58-77.

http://www.acaoeducativa.org.br/downloads/parte1.pdf acessado em 12 de junho de 2007.

FAUSTO, Boris. A Revolução de 1930: historiografia e história. $2^{\mathrm{a}}$ ed., São Paulo: Ed. Brasiliense, 1972.

MANFREDI, Sílvia Maria. Política e Educação Popular. $2^{a}$ ed., São Paulo: Ed. Cortez, 1981.

MEDEIROS, Maria do Socorro de Araújo. A Formação de Professores para a Educação de Adultos no Brasil: da história à ação. Palma de Malorca: Tese de Doutorado pela Universitat de les Illes Balears, 1999.

OLIVEIRA, Romualdo L. Portela. Educação de Jovens e Adultos: o direito à educação. In: Mesa Redonda: Direitos Educativos e a EJA no Brasil. $16^{\circ}$ Congresso de Leitura do Brasil - COLE, X Seminário de Educação de Jovens e Adultos. Campinas: UNICAMP, 11 a 13 de julho de 2007, http://www.alb.com.br/anais16/prog_pdf/prog01_01.pdf, acessado em 05 de maio de 2008.

RIBEIRO, Vera Maria Masagão (coord.). Educação de Jovens e Adultos: proposta curricular para o $1^{o}$ segmento do ensino fundamental. São Paulo: Ação Educativa Assessoria, Pesquisa, Informação; Brasília: Ministério Da Educação E Do Desporto, 1997. http://www.scielo.br/pdf/ccedes/v21n55/5541.pdf acessado em 08 de agosto de 2007.

SANTOS, Edicleia Aparecida Alves dos; STREMEL, Margareth Leonardi Kuhn; OLIVEIRA, Rita de Cássia da Silva. A Necessidade de Reinventar a História da Educação de Jovens e Adultos no Brasil. Universidade Estadual de Ponta Grossa UEPG, 2004.

http://www.cereja.org.br/arquivos_upload/edicleia_margareth_rita_necessidade_\%20reinv entar_eja.pdf artigo em PDF acessado em 24 de setembro de 2007.

STEPHANOU, Maria; BASTOS, Maria Helena (orgs). Histórias e Memórias da Educação no Brasil. Vol. III. Petrópolis: Vozes, 2005.

\footnotetext{
* Graduando em Teologia pela Faculdades EST e em Pedagogia pela Pontifícia Universidade Católica do Rio Grande do Sul.

${ }^{1}$ STEPHANOU, Maria; BASTOS, Maria Helena (orgs). Histórias e Memórias da Educação no Brasil, 2005 , p. 259.

2 AGUIAR, Raimundo Helvécio Almeida. Educação de Adultos no Brasil: políticas de (des)legitimação, 2001, p. 10-12.

${ }^{3}$ MEDEIROS, Maria do Socorro de Araújo. A Formação de Professores para a Educação de Adultos no Brasil: da História à Ação. Mallorca, 1999, p. 180.

${ }^{4}$ STEPHANOU; BASTOS (orgs), 2005, p. 260-261.

${ }^{5}$ STEPHANOU; BASTOS (orgs), 2005, p. 262.

${ }^{6}$ MEDEIROS. 1999, p. 180.

${ }^{7}$ STEPHANOU; BASTOS (orgs), 2005, p. 262-264.

${ }^{8}$ MANFREDI, 1981, p. 26.

${ }^{9}$ MANFREDI, 1981, p. 26.

${ }^{10}$ AGUIAR. 2001, p. 14.

${ }^{11}$ MEDEIROS. 1999, p. 182.
} 


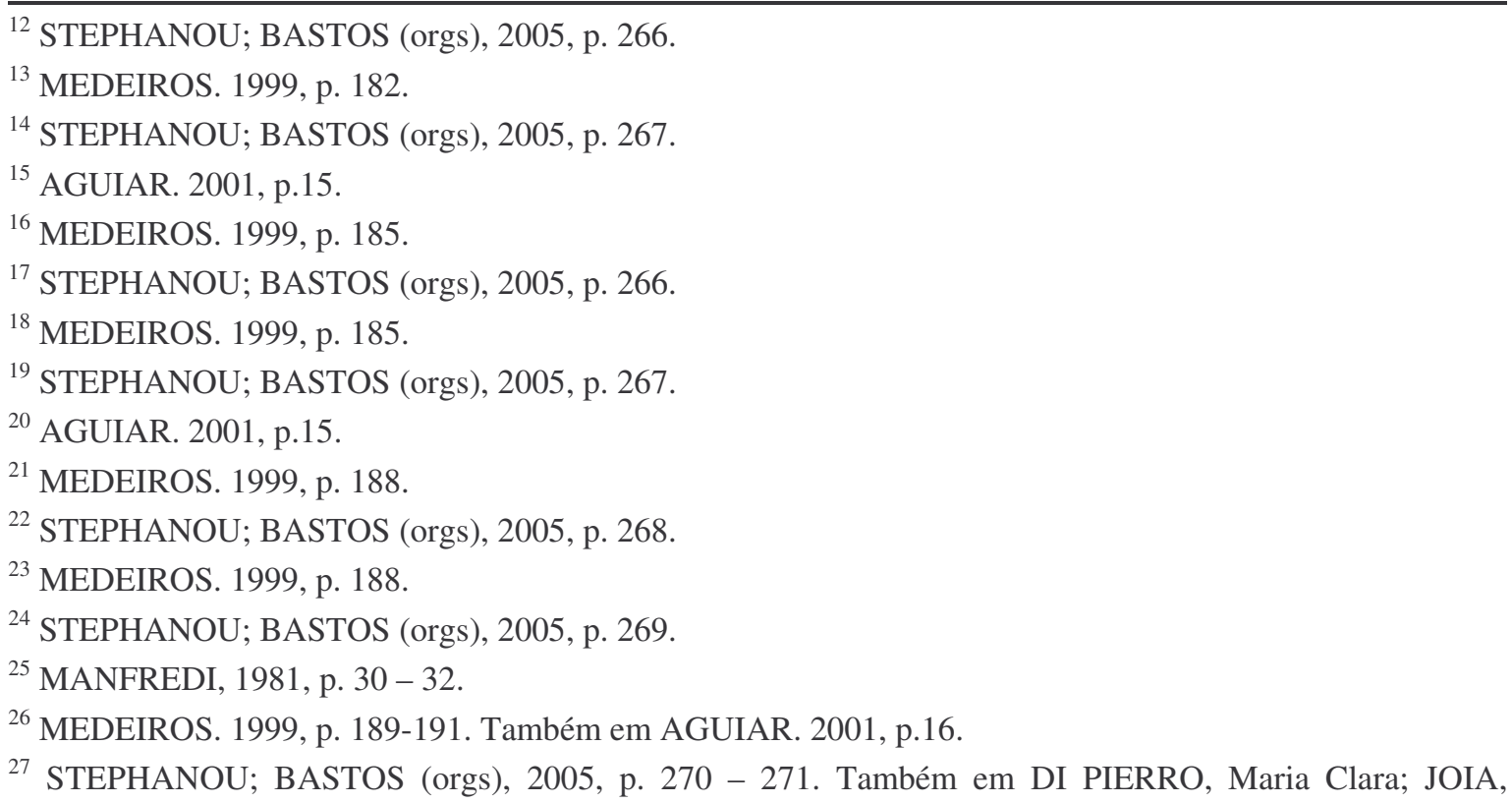
Orlando; RIBEIRO, Vera Masagão. Visões da Educação de Jovens e Adultos no Brasil. Cadernos Cedes, 2001, p. 61.

${ }^{28}$ MANFREDI, 1981, p. 29 - 30.

${ }^{29}$ OLIVEIRA, Romualdo L. Portela. Educação de Jovens e Adultos: o direito à educação, 2007, p. 4.

${ }^{30}$ SANTOS, Edicleia Aparecida Alves dos; STREMEL, Margareth Leonardi Kuhn; OLIVEIRA, Rita de Cássia da Silva. A Necessidade de Reinventar a História da Educação de Jovens e Adultos no Brasil. 2004, p. 08.

${ }^{31} \mathrm{O}$ direito dos jovens e adultos à educação é resguardado também nos artigos 37 e 38 da LDB. De acordo com o artigo 37, a EJA será "destinada àqueles que não tiveram acesso ou continuidade de estudos no ensino fundamental e médio”. Dessa forma, esse direito é assegurado às pessoas jovens e adultas, que no decorrer de suas vidas foram marginalizadas. Os dois parágrafos do artigo 37 estabelecem que o direito é reservado a gratuidade e o estímulo ao acesso e a permanência destas pessoas na EJA. No artigo 38 fica estabelecido um possível modo de como ocorrerá de maneira prática o direito à EJA. Assim, é colocado que "os sistemas de ensino manterão cursos e exames supletivos, que compreenderão a base nacional comum do currículo, habilitando ao prosseguimento de estudos em caráter regular". Com isso, a execução da EJA poderá ocorrer a partir de supletivos que estarão em acordo com a base curricular nacional, mas para isto deve-se obedecer a seguinte norma de idade para ensino fundamental para maiores de quinze anos e para o ensino médio para maiores de dezoito anos. Também o parágrafo 2 do artigo 38 da LDB garante por meio de exames os conhecimentos e habilidades adquiridas pelos educandos por meios informais, como por exemplo, através de experiências em sua profissão.

${ }^{32}$ ANTUNES, Denise Dalpiaz. Relatos significativos de professores e alunos na Educação de Jovens e Adultos e sua auto-imagem e auto-estima, 2006, p. 33.

${ }^{33}$ STEPHANOU; BASTOS (orgs), 2005, p. 271-272. Também em RIBEIRO, Vera Maria Masagão (coord.). Educação de Jovens e Adultos: proposta curricular para o $\mathbf{1}^{\circ}$ segmento do ensino fundamental. São Paulo/Brasília, 1997, p. 33.

${ }^{34}$ STEPHANOU; BASTOS (orgs), 2005, p. 273.

35 DI PIERRO, Maria Clara; GRACIANO, Mariângela. A Educação de Jovens e Adultos no Brasil: informe apresentado à oficina regional da UNESCO para América Latina y Caribe. São Paulo, 2003, p. $08-09$.

Artigo recebido em: 05/01/109

Aprovado em: 1/8/2009 